\title{
Pengaruh Pendidikan Kesehatan Masa Nifas Terhadap Kemampuan Perawatan Mandiri Ibu Nifas Post Sectio Caesarea (SC)
}

\author{
Anafrin Yugistyowati ${ }^{1}$
}

${ }^{1}$ Sekolah Tinggi Ilmu Kesehatan Alma Ata Yogyakarta

\begin{abstract}
Abstrak
Ibu melahirkan dengan SC membutuhkan waktu yang lebih lama untuk mengembalikan organ-organ tubuh kembali seperti sebelum hamil. Dalam kenyataanya di lapangan, masih sering dijumpai keterlambatan ibu Post SC untuk mobilisasi dini dan perawatan mandiri. Peran dan tanggung jawab perawat sangat diperlukan dalam pemberian informasi dan pendidikan kesehatan sebagai upaya untuk menghindari self care deficit, komplikasi perdarahan, dan infeksi Post SC, serta menurunkan angka kematian maternal. Untuk mengetahui pengaruh pendidikan kesehatan terhadap kemampuan perawatan mandiri ibu nifas Post SC, penelitian dilakukan dengan metode eksperimen dan menggunakan rumus Independent Samples T-Test. Sampel berjumlah 20 responden dengan teknik pengambilan sampel Quota Sampling. Uji kemampuan perawatan mandiri dengan menggunakan lembar observasi. Simpulan dari hasil penelitian ini adalah ada pengaruh pendidikan kesehatan masa nifas terhadap kemampuan perawatan mandiri ibu nifas Post SC dengan taraf signifikansi 0,000.
\end{abstract}

Kata Kunci: pendidikan kesehatan masa nifas, sectio caesarea (SC), perawatan mandiri

Info artikel:

Artikel dikirim pada 03 september 2013

Artikel diterima pada 05 september 2013

\section{PENDAHULUAN}

Kematian pada ibu hamil dan bersalin adalah masalah besar bagi negara berkembang. Kematian saat melahirkanmenjadi faktor utama mortalitas wanita pada masa puncak produktivitasnya. Pelayanan kesehatan maternal dan neonatalmerupakan salah satu unsur penentu status kesehatan masyarakat, yaitu dengan diketahuinya Angka Kematian Ibu (AKI) dan Angka Kematian Bayi (AKB). Data AKI di Indonesia masih tinggi, menurut Survey Kesehatan Rumah Tangga (SKRT) tahun 2001 yaitu 369 per 100.000 kelahiran hidup, tetapi ada penurunan pada tahun 2003 yaitu 307 per 100.000 kelahiran hidup (1).

Penyebab kematian ibu di Indonesia adalah perdarahan $(67 \%)$, infeksi $(8 \%)$, eklampsia $(7 \%)$, abortus (10\%), dan komplikasi persalinan (9\%).Angka kematian ibu karena tindakan operatif khususnya Sectio Caesarea(SC)sekitar 2 sampai 46 kali lebih tinggi daripada persalinan pervaginam (2). AKI pada kasus SC adalah 22 per 100.000 untuk seluruh kasus SC. Namun untuk angka kematian yang secara langsung disebabkan oleh $S C$ adalah 5,8 per 100.000 kasus. Ancaman utama bagi wanita yang menjalani SC menyebabkan tingginya AKI berasal dari tindakan anestesi, sepsis yang berat, dan serangan tromboemboli (3).

Sectio Caesarea adalah tindakan operatif yang bertujuan untuk melahirkan bayi melalui tindakan pembedahan dengan membuka dinding perut dan dinding rahim. Melahirkan dengan cara operasi SC tidak bisa terlepas dari risiko yang mungkin dialami akibat pembedahan, baik dari segi kesehatan ibu maupun bayinya(4).

Melahirkan dengan SC membutuhkan waktu yang cukup lama untuk mengembalikan organ-organ tubuhseperti sebelum hamil. Operasi SCmemerlukan perawatan yang lebih lama dibandingkan dengan persalinan yang dilakukan secara alami, yaitu sekitar 4-6 minggu (5). Faktor masih banyaknya ketidaknyamanan berupa rasa nyeri dan sakit karena luka operatif dapat mempengaruhi kondisi psikologis berupa kecemasan, kekecewaan, rasa takut, frustasi karena kehilangan kontrol, dan kehilangan harga diri yang terkait dengan perubahan citra diri (4). 
Teori Orem menjelaskan tentang adanya kemampuan individu dalam memenuhi kebutuhan hidup sehari-hari guna mencapai kesehatan yang optimal, namun apabila kebutuhan tersebut tidak dapat terpenuhi oleh ketidakmampuan individu tersebutakan mengalami self care deficit atau kurang perawatan diri.

Pada keadaan seperti ini sangat penting adanya peran perawat dalam membantu mengembalikan kesehatan individu tersebut. Perawat dapat memberikan bantuan kepada klien dengan melakukan prosedur yang tepat melalui pemberian asuhan keperawatan, memperbaiki instruksi yang diberikan, dan pemberian informasi tentang kesehatan secara individual, sehingga secara bertahap klien mampu memenuhi kebutuhannya sendiri (6)

Perawatan yang dibutuhkan ibu selama masa nifas yaitu membantu ibu memantau dan mempertahankan kesehatannya dengan memberikan informasi kesehatan dan keterampilan yang tepat (6). Pada masa nifas perawatan yang dibutuhkan oleh klien antara lain: pemenuhan kebutuhan nutrisi, mobilisasi, eliminasi, personal hygiene, perawatan payudara, teknik menyusui yang benar, perawatan luka jahit agar tidak terjadi infeksi, dan pengawasan involusi uteri (5).

Kasus SC di Propinsi DIY menurut profil kesehatan tahun 2001, sebanyak 1.477 kasus merupakan kasus rujukan di Rumah Sakit Umum (RSU) dan Rumah Sakit Bersalin (RSB), sedangkan sebanyak 559 kasus merupakan kasus non rujukan(4). Berdasarkan studi pendahuluan melalui hasil survei dan wawancara di RS PKU Muhammadiyah Yogyakarta didapatkan data kasus SC pada bulan Februari sampai dengan April 2010 berjumlah 66 kasus. Beberapa klien dan keluarga menyatakan pentingnya penjelasan dan motivasi dari perawat tentang perawatan mandiri masa nifas, sedangkan pelaksanaan di ruangan masih bersifat rutinitas, tidak terstruktur, dan tanpa menggunakan pedoman buku yang lengkap, serta tidak dilengkapi dengan media pendidikan kesehatan. Kondisi ini memungkinkan informasi yang diperoleh klien tidak menyeluruh dan berakibat masih banyak dijumpai pasien post SC mengalami keterlambatan untuk mobilisasi dan keterlambatan untuk kesiapan perawatan mandiri baik selama di Rumah Sakit ataupun saat berada di rumah.

Penelitian ini bertujuan untuk mengetahui pengaruh pendidikan kesehatan masa nifas terhadap kemampuan perawatan mandiri ibu nifas Post SC di RS PKU Muhammadiyah Yogyakarta.

\section{BAHAN DAN METODE}

Penelitian ini menggunakan metode eksperimen, dengan desain penelitian Static Group Comparison dimana terdapat kelompok pembanding (kontrol).
Populasi pada penelitian ini adalah semua ibu Post SC yang dirawat di bangsal Sakinah kelas II dan III RS PKU Muhammadiyah Yogyakarta. Teknik sampling yang digunakan adalah Quota sampling, jumlah sampel 20 respondendengan kategori: 10 responden untuk kelompok eksperimen dan 10 responden untuk kelompok kontrol. Kriteriapengambilan sampel antara lain: persalinan SC yang pertama tanpa komplikasi, menggunakan jenis anestesi spinal, dan kondisi psikologis ibu baik, yaitu kehamilan yang diinginkan.

Alat pengumpulan data yang digunakan adalah lembar observasi yangterdiri dari 20 item kemampuan perawatan mandiri Post SCdengan komponen antara lain mobilisasi dini, perawatan payudara, dan teknik menyusui. Teknik pengumpulandata menggunakan teknik wawancara dan pengamatan sistematis. Analisis data diuji dengan statistik Independent Samples T-Testdengan rumus $\mathrm{dk}(\mathrm{n} 1+\mathrm{n} 2-2)(7)$.

\section{HASIL DAN PEMBAHASAN}

Penelitian ini dilakukan di bangsal nifas (Sakinah) dari tanggal 1 Mei sampai 4 Juni 2010.Responden penelitian merupakan ibu nifas Post SC dengan jumlah responden sebanyak 20 orang, terdiri dari 10 orang kelompok eksperimen dan 10 orang kelompok kontrol.

\section{Karakteristik Responden Penelitian}

Tabel. 1 Distribusi Frekuensi Berdasarkan Umur Ibu Nifas Post SC di Bangsal Sakinah RS PKU Muhammadiyah Yogyakarta

\begin{tabular}{cccc}
\hline No & Karakteristik Umur & Frekuensi & Persentase \\
\hline 1 & $14-24$ Tahun & 1 & $5 \%$ \\
2 & $25-35$ Tahun & 15 & $75 \%$ \\
3 & $36-46$ Tahun & 4 & $20 \%$ \\
\hline Total & & 20 & $100 \%$ \\
\hline
\end{tabular}

Sumber : Data Primer

Berdasarkan tabel. 1 frekuensi terbanyak adalah responden berumur 25 - 35 tahun sebanyak 15 orang $(75 \%)$ dan frekuensi terendah adalah responden berumur $14-24$ tahun sebanyak 1 orang (5\%).

Tabel. 2 Distribusi Frekuensi Berdasarkan Pendidikan Ibu Nifas Post SC di Bangsal Sakinah RS PKU Muhammadiyah Yogyakarta

\begin{tabular}{cccc}
\hline No & $\begin{array}{c}\text { Karakteristik } \\
\text { Pendidikan }\end{array}$ & Frekuensi & Persentase \\
\hline 1 & SLTP & 2 & $10 \%$ \\
2 & SLTA & 10 & $50 \%$ \\
3 & PT / Akademi & 8 & $40 \%$ \\
\hline & Total & 20 & $100 \%$ \\
\hline
\end{tabular}

Sumber : Data Primer 
Berdasarkan Tabel. 2 menunjukkan frekuensi terbanyak adalah responden berpendidikan SLTA sebanyak 10 orang $(50 \%)$ dan frekuensi terendah adalah responden berpendidikan SLTP sebanyak 2 orang $(10 \%)$.

Tabel. 3 Distribusi Frekuensi Berdasarkan Pekerjaan Ibu Nifas Post SC di Bangsal Sakinah RS PKU Muhammadiyah Yogyakarta

\begin{tabular}{llll}
\hline No & \multicolumn{1}{c}{$\begin{array}{c}\text { Karakteristik } \\
\text { Pekerjaan }\end{array}$} & Frekuensi & Persentase \\
\hline 1 & IRT & 9 & $45 \%$ \\
2 & Wiraswasta & 8 & $40 \%$ \\
3 & Pramuniaga & 1 & $5 \%$ \\
4 & PNS & 2 & $10 \%$ \\
\hline \multicolumn{2}{c}{ Total } & 20 & $100 \%$ \\
\hline
\end{tabular}

Sumber : Data Primer

Berdasarkan tabel. 3 frekuensi terbanyak adalah responden yang tidak bekerja atau sebagai Ibu Rumah Tangga (IRT) sebanyak 9 orang (45\%) dan frekuensi terendah adalah responden dengan pekerjaan sebagai pramuniaga sebanyak 1 orang (5\%).

Kemampuan Perawatan Mandiri lbu Nifas Post SC Berdasarkan Karakteristik Responden Pada Kelompok Eksperimen dan Kontrol

Berdasarkan Tabel. 4 menunjukkan bahwa kemampuan perawatan mandiri berdasar karakteristik umur pada kelompok eksperimen dengan kategori kemampuan perawatan tertinggi yaitu kemampuan supportif edukatif sebanyak 7 orang $(70 \%)$ pada umur 25 - 35 tahun.

Berdasarkan Tabel. 5 menunjukkan bahwa kemampuan perawatan mandiri berdasar karakteristik pendidikan pada kelompok eksperimen dengan kategori kemampuan perawatan tertinggi yaitu kemampuan supportif edukatif sebanyak 4 orang (40 \%) dengan pendidikan PT / Akademi.

Berdasarkan Tabel. 6 menunjukkan bahwa kemampuan perawatan mandiri berdasar karakteristik umur pada kelompok kontrol dengan kategori kemampuan perawatan tertinggi yaitu kemampuan bantuan sebagian sebanyak 7 orang $(70 \%)$ pada umur 25 - 35 tahun. Berdasarkan Tabel. 7 menunjukkan bahwa kemampuan perawatan mandiri berdasar tingkatan pendidikan pada kelompok kontrol dengan kategori kemampuan perawatan tertinggi yaitu kemampuan bantuan sebagian sebanyak 6 orang (60\%) dengan pendidikan SLTA; sedangkan kemampuan perawatan terendah yaitu kemampuan supportif edukatif sebanyak 1 orang (10 $\%)$ dengan pendidikan SLTA.

Berdasarkan Tabel. 8 di atas, menunjukkan bahwa kemampuan perawatan mandiri ibu nifas Post SC pada kelompok eksperimen dengan kategori kemampuan perawatan tertinggi yaitu kemampuan supportif edukatif sebanyak 8 orang (80 $\%$ ); sedangkan kelompok kontrol, dengan kategori kemampuan perawatan tertinggiyaitu kemampuan bantuan sebagian sebanyak 9 orang $(90 \%)$.

Tabel. 4 Distribusi Silang Kemampuan Perawatan Mandiri Ibu Nifas Post SC Berdasarkan Karakteristik Umur Pada Kelompok Eksperimen di Bangsal Sakinah RS PKU Muhammadiyah Yogyakarta

\begin{tabular}{|c|c|c|c|c|c|c|c|c|}
\hline \multirow{3}{*}{ Karakteristik Umur } & \multicolumn{6}{|c|}{ Kemampuan Perawatan Mandiri } & \multirow{3}{*}{ Jumlah } & \multirow{3}{*}{$\%$} \\
\hline & \multicolumn{2}{|c|}{ Supportif \& Edukatif } & \multicolumn{2}{|c|}{ Bantuan Sebagian } & \multicolumn{2}{|c|}{ Bantuan Penuh } & & \\
\hline & $\mathbf{F}$ & $\%$ & $\mathbf{F}$ & $\%$ & $\mathbf{F}$ & $\%$ & & \\
\hline $14-24$ tahun & 0 & 0 & 1 & 10 & 0 & 0 & 1 & 10 \\
\hline $25-35$ tahun & 7 & 70 & 0 & 0 & 0 & 0 & 7 & 70 \\
\hline $36-46$ tahun & 1 & 10 & 1 & 10 & 0 & 0 & 2 & 20 \\
\hline Jumlah & 8 & 80 & 2 & 20 & 0 & 0 & 10 & 100 \\
\hline
\end{tabular}

Sumber: Data Primer

Tabel. 5 Distribusi Silang Kemampuan Perawatan Mandiri Ibu Nifas Post SC Berdasarkan Karakteristik Pendidikan Pada Kelompok Eksperimen di Bangsal Sakinah RS PKU Muhammadiyah Yogyakarta

\begin{tabular}{|c|c|c|c|c|c|c|c|c|}
\hline \multirow{3}{*}{$\begin{array}{c}\text { Karakteristik } \\
\text { Pendidikan }\end{array}$} & \multicolumn{6}{|c|}{ Kemampuan Perawatan Mandiri } & \multirow{3}{*}{ Jumlah } & \multirow{3}{*}{$\%$} \\
\hline & \multicolumn{2}{|c|}{ Supportif \& Edukatif } & \multicolumn{2}{|c|}{ Bantuan Sebagian } & \multicolumn{2}{|c|}{ Bantuan Penuh } & & \\
\hline & $\mathbf{F}$ & $\%$ & $\mathbf{F}$ & $\%$ & $\mathbf{F}$ & $\%$ & & \\
\hline SLTP & 1 & 10 & 1 & 10 & 0 & 0 & 2 & 20 \\
\hline SLTA & 3 & 30 & 0 & 0 & 0 & 0 & 3 & 30 \\
\hline PT / Akademi & 4 & 40 & 1 & 10 & 0 & 0 & 5 & 50 \\
\hline Jumlah & 8 & 80 & 2 & 20 & 0 & 0 & 10 & 100 \\
\hline
\end{tabular}

Sumber: Data Primer 
Tabel. 6 Distribusi Silang Kemampuan Perawatan Mandiri Ibu Nifas Post SC Berdasarkan Karakteristik Umur Pada Kelompok Kontrol di Bangsal Sakinah RS PKU Muhammadiyah Yogyakarta

\begin{tabular}{|c|c|c|c|c|c|c|c|c|}
\hline \multirow{3}{*}{$\begin{array}{l}\text { Karakteristik } \\
\text { Pendidikan }\end{array}$} & \multicolumn{6}{|c|}{ Kemampuan Perawatan Mandiri } & \multirow{3}{*}{ Jumlah } & \multirow{3}{*}{$\%$} \\
\hline & \multicolumn{2}{|c|}{ Supportif \& Edukatif } & \multicolumn{2}{|c|}{ Bantuan Sebagian } & \multicolumn{2}{|c|}{ Bantuan Penuh } & & \\
\hline & $\mathbf{F}$ & $\%$ & $F$ & $\%$ & $F$ & $\%$ & & \\
\hline $25-35$ tahun & 1 & 10 & 7 & 70 & 0 & 0 & 8 & 80 \\
\hline $36-46$ tahun & 0 & 0 & 2 & 20 & 0 & 0 & 2 & 20 \\
\hline Jumlah & 1 & 10 & 9 & 90 & 0 & 0 & 100 & 100 \\
\hline
\end{tabular}

Sumber: Data Primer

Tabel. 7 Distribusi Silang Kemampuan Perawatan Mandiri Ibu Nifas Post SC Berdasarkan Karakteristik Pendidikan Pada Kelompok Kontrol di Bangsal Sakinah RS PKU Muhammadiyah Yogyakarta

\begin{tabular}{|c|c|c|c|c|c|c|c|c|}
\hline \multirow{3}{*}{$\begin{array}{c}\text { Karakteristik } \\
\text { Pendidikan }\end{array}$} & \multicolumn{6}{|c|}{ Kemampuan Perawatan Mandiri } & \multirow{3}{*}{ Jumlah } & \multirow{3}{*}{$\%$} \\
\hline & \multicolumn{2}{|c|}{ Supportif \& Edukatif } & \multicolumn{2}{|c|}{ Bantuan Sebagian } & \multicolumn{2}{|c|}{ Bantuan Penuh } & & \\
\hline & $\mathbf{F}$ & $\%$ & $\mathbf{F}$ & $\%$ & $\mathbf{F}$ & $\%$ & & \\
\hline SLTA & 1 & 10 & 6 & 60 & 0 & 0 & 7 & 70 \\
\hline PT / Akademi & 0 & 0 & 3 & 30 & 0 & 0 & 3 & 30 \\
\hline Jumlah & 1 & 10 & 9 & 90 & 0 & 0 & 100 & 100 \\
\hline
\end{tabular}

Sumber: Data Primer

Tabel. 8 Distribusi Silang Kemampuan Perawatan Mandiri lbu Nifas Post SC Pada kelompok Eksperimen dan Kelompok Kontrol di Bangsal Sakinah RS PKU Muhammadiyah Yogyakarta

\begin{tabular}{|c|c|c|c|c|c|c|c|c|}
\hline \multirow{3}{*}{ Kelompok } & \multicolumn{6}{|c|}{ Kemampuan Perawatan Mandiri } & \multirow{3}{*}{ Jumlah } & \multirow{3}{*}{$\%$} \\
\hline & \multicolumn{2}{|c|}{ Supportif \& Edukatif } & \multicolumn{2}{|c|}{ Bantuan Sebagian } & \multicolumn{2}{|c|}{ Bantuan Penuh } & & \\
\hline & $\mathbf{F}$ & $\%$ & $\mathbf{F}$ & $\%$ & $\mathbf{F}$ & $\%$ & & \\
\hline Eksperimen & 8 & 80 & 2 & 20 & 0 & 0 & 10 & 100 \\
\hline Kontrol & 1 & 10 & 9 & 90 & 0 & 0 & 10 & 100 \\
\hline Jumlah & 9 & 90 & 11 & 110 & 0 & 0 & 20 & 200 \\
\hline
\end{tabular}

Sumber : Data Primer

\section{Pembahasan}

Pada tabel. 4 menunjukkan bahwa kemampuan perawatan mandiri berdasarkan karakteristik umur pada kelompok eksperimen antara lain: kemampuan tertinggi yaitu supportif edukatif sebanyak 7 orang (70 \%) pada umur 25 - 35 tahun dan kemampuan perawatan terendah yaitu kemampuan bantuan sebagian sebanyak 1 orang (10\%) pada umur 14 24 tahun. Kematangan atau kedewasaan seseorang menjadi ibu dipengaruhi oleh faktor usia (8). Pada usia melahirkan di atas 25 tahun, kemandirian atau kedewasaan lebih baik dibandingkan kelompok usia di bawahnya. Meskipun demikian tidak terlepas dengan semakin bertambahnya umur seseorang maka faktor pengalaman melahirkan dan merawat anak pertama, faktor kesiapan fisik dan psikis juga mempengaruhi kemampuan dalam perawatan mandirinya.

Pada tabel. 6 pada kelompok kontrol menunjukkan kemampuan tertinggi yaitu kemampuan bantuan sebagian sebanyak 7 orang (70 \%) pada umur 25 - 35 tahun; sedangkan kemampuan perawatan terendah yaitu kemampuan supportif edukatif sebanyak 1 orang (10\%) pada umur 25
- 35 tahun. Hal ini menunjukkan pada kelompok responden dengan umur 25 - 35 tahun tingkat kemampuan perawatan mandiri semakin rendah dibandingkan dengan kelompok eksperimen, yaitu dengan kemampuan bantuan sebagian. Berdasarkan hasil penelitian ini, faktor umur berpengaruh tetapi jika tidak ada pemberian informasi dan pendidikan kesehatanmaka tujuan atau hal yang diharapkan dari perawatan kesehatan juga tidak optimal. Teori Notoatmodjo (2003) juga menyatakan bahwa proses pembelajaran diharapkan dapat memperoleh pengetahuan yang lebih baik, khususnya tentang pelaksanaan perawatan kesehatan yang baik, sehingga pendidikan membawa akibat terhadap perubahan perilaku sasaran.

Tabel. 5 dapat disimpulkan bahwa kemampuan perawatan mandiri berdasarkan karakteristik pendidikan pada kelompok eksperimen yaitu kemampuan supportif edukatif sebanyak 4 orang (40\%) dengan pendidikan perguruan tinggiatau akademi; sedangkan kemampuan perawatan terendah yaitu kemampuan supportif edukatif sebanyak 1 orang (10\%) dengan pendidikan SLTP. Hal ini menunjukkan semakin tinggi tingkat pendidikan maka kemampuan untuk menyerap informasi yang 
ada juga semakin baik, sehingga semakin optimal untuk melakukan hal-hal yang diinstruksikan. Teori yang diungkapkan oleh Notoatmodjo (2002) bahwa pengetahuan merupakan domain yang sangat penting bagi terbentuknya tindakan seseorang. Perilaku yang didasari oleh pengetahuan akan lebih mantab daripada perilaku yang tidak didasari oleh pengetahuan.

Saefuddin (2001) menjelaskan bahwa, pendidikan kesehatan dan konseling merupakan proses pemberian informasi yang obyektif dan lengkap, dilakukan secara sistematik dengan panduan keterampilan komunikasi interpersonal, teknik penyampaian, dan penguasaan pengetahuan klinik. Pendidikan kesehatan yang diberikan didalamnya mengandung unsur-unsur tentang informasi dan pengetahuan mengenai masa nifas dan perubahanperubahannya baik fisiologis maupun psikologis. Selanjutnya dengan pengetahuan-pengetahuan itu akan menimbulkan kesadaran mereka, dan akhirnya akan menyebabkan orang berperilaku sesuai dengan pengetahuan yang dimilikinya itu. Hasil atau perubahan perilaku dengan cara ini akan membutuhkan waktu yang lama, tetapi perubahan yang dicapai akan bersifat langgeng karena didasari pada kesadaran mereka sendiri bukan karena paksaan.

Pengaruh pendidikan kesehatan masa nifas terhadap kemampuan perawatan mandiri ibu Post SCdijelaskan pada Tabel.9; sebanyak 10 responden yang diberi pendidikan kesehatan masa nifas, persentase terbanyak yaitu responden dengan kemampuan supportif edukatif yaitu sebanyak 8 orang (80\%); sedangkan dari 10 responden yang tidak diberi pendidikan kesehatan masa nifas, persentase terbanyak yaitu responden dengan kemampuan bantuan sebagian yaitu sebanyak 9 orang $(90 \%)$. Hal ini menunjukkan bahwa pendidikan kesehatan masa nifas mempunyai pengaruh terhadap kemampuan perawatan mandiri ibu nifas Post SC.

Hasil uji statistik Independent Samples T-Test didapatkan hasil t hitung sebesar 4,664 dengan taraf signifikansi 0,000 dan $t$ tabel sebesar 2,101 dengan taraf signifikansi 0,05 . Dari hasil penelitian didapatkan bahwa thitung lebih besar dari t tabel, maka Ha diterima yang artinya ada pengaruh pendidikan kesehatan yang diberikan terhadap kemampuan perawatan mandiri.

Dalam penelitian ini, menggunakan metode yang bervariasi, yaitu dengan ceramah, demonstrasi, dan menggunakan alat bantu leaflet dalam penyampaian pendidikan kesehatan masa nifas. Pada pelaksanaanya ibu Post SC memiliki rasa keingintahuan yang besar dengan adanya pertanyaan-pertanyaan yang disampaikandan pelaksanaan perawatan mandiri ibu Post SC semakin baik jika dibandingkan dengan kelompok kontrol yang tidak diberikan pendidikan kesehatan masa nifas.

Dengan metode dan media pendidikan kesehatan yang semakin bervariasi dan menarik, harapannya penyampaian pendidikan semakin efektif, pesan-pesan kesehatan dapat disampaikan dengan jelas, dan ibu Post SC dapat menerima pesan tersebut dengan jelas pula.

\section{SIMPULAN DAN SARAN}

Berdasarkan hasil penelitian ini dapat disimpulkan sebagai berikut:

1. Terdapat pengaruh pendidikan kesehatan masa nifas terhadap kemampuan perawatan mandiri ibu nifas Post SC di RS PKU Muhammadiyah Yogyakarta dengan thitung sebesar 4,664 dan $t$ tabel sebesar 2,101 dengan taraf signifikansi 0,05 .

2. Kemampuan perawatan mandiri ibu nifas Post SC yang diberikan pendidikan kesehatan masa nifas sebagian besar merupakan responden dalam kategori kemampuan supportif edukatif yaitu sebanyak 8 orang $(80 \%)$.

3. Kemampuan perawatan mandiri ibu nifas Post SC yang tidak diberikan pendidikan kesehatan masa nifas sebagian besar merupakan responden dalam kategori kemampuan bantuan sebagian yaitu sebanyak 9 orang $(90 \%)$.

\section{RUJUKAN}

1. Depkes RI. 2003. Pedoman pemantauan wilayah setempat kesehatan ibu dan anak (PWS-KIA). Depkes: Jakarta

2. Wiknjosastro, H. 1999.IImu kebidanan. Yayasan Bina Pustaka Sarwono Prawirohardjo: Jakarta

3. Donald, M. 1995. Obstetri William, Edisi 18. EGC: Jakarta

4. Kasdu, D. 2003.Operasi Caesar masalah dan solusinya. Puspa Swara: Jakarta

5. Saefuddin, AB. 2000.Buku acuan nasional pelayanan kesehatan maternal dan neonatal. JNPKKR: Jakarta

6. Hidayat, A.A. 2004.Pengantar konsep dasar keperawatan. Salemba Medika: Jakarta.

7. Sugiyono. 2004.Statistik untuk penelitian cetakan ke-8. Alfa beta: Bandung

8. Mary, H. 2003.Panduan pelayanan kesehatan maternal dan neonatal. EGC: Jakarta

9. Notoatmodjo, 2003, Pendidikan kesehatan dan perilaku kesehatan. Rineka Cipta: Jakarta

10. Notoatmodjo. 2002.Pendidikan dan ilmu perilaku kesehatan. Renika Cipta: Jakarta 